\title{
Introducción a la teoría de los modos de intercambio
}

\section{An introduction to Modes of Exchange}

\author{
Kojin Karatani \\ Universidad de Tokio \\ kkaratani@gmail.com
}

Resumen: En La estructura de la historia mundial (edición japonesa 2010; edición inglesa 2014), señalé la necesidad de transponer la noción central de "modos de producción" por la de "modos de intercambio". En este trabajo quiero explicar esto. A través de una metáfora arquitectónica, la ortodoxia marxista ha explicado la historia de las formaciones sociales en términos de los modos de producción, que existen como base económica (fundamento) y por los cuales se determina la superestructura política-ideal. Un modo de producción se constituye por las fuerza productivas, que están constituidas por las relaciones entre el ser humano y la naturaleza, y las relaciones de producción, que provienen de las relaciones entre los seres humanos. Yo no me opongo a la idea de que la historia de las formas sociales está determinada por la base económica, pero, desde mi punto de vista, esta base no está en los modos de producción, sino en los modos de intercambio. Lo que yo llamo modos de intercambio incluye a ambas relaciones, entre la naturaleza y los seres humanos, y entre los propios seres humanos.

Palabras clave: Marxismo, intercambios históricos, religión y ética, crédito y dinero, nomadismo. 
Abstract: In The Structure of World History (2010; english edition 2014), I proposed the notion of switching "from modes of production to modes of exchange". Here, I would like to provide a simple explanation of this. Orthodox Marxist theory, using an architectural metaphor, explains the history of social forms in terms of modes of production, which form the economic base (foundation), and of the political or ideational superstructures that are determined by that base. A mode of production consists of the productive forces, which arise from the relations between humans and nature, and the relations of production, which are constituted by the relations between humans. I do not oppose the idea that the history of social forms is determined by the economic base, but in my view that base consists not of modes of production, but rather modes of exchange. What I call modes of exchange includes both relations between nature and humans and relations between humans.

Keywords: Marxism, Historical exchanges, Religion and ethics, Credit and money, Nomadism.

Recibido: 19 de septiembre de 2019

Aprobado: 20 de octubre de 2019 https://dx.doi.org/10.15174/rv.vi25.503

Z n La estructura de la historia mundial (edición japonesa 2010; Eedición inglesa 2014), yo propuse un cambio de punto de vista bajo la expresión "de los modos de producción a los modos de intercambio", sobre el cual quisiera dar aquí una breve explicación. La teoría oficial del marxismo ha explicado, recurriendo a una metáfora arquitectónica, la historia de las formaciones sociales en términos de los modos de producción, que existen como base económica (cimientos) y por los cuales se determina la superes- 
tructura política-ideal. Los modos de producción consisten en la fuerza productiva que surge de las relaciones entre el hombre y la naturaleza, y en las relaciones de producción que provienen de las relaciones entre los hombres. No me opongo a la idea de que la historia de las formaciones sociales está condicionada por la base económica, pero en mi perspectiva, esta base no consiste en los modos de producción sino en los modos de intercambio. Y los modos de intercambio que propongo abarcan tanto las relaciones entre el hombre y la naturaleza como las relaciones entre los hombres. ${ }^{l}$

Pienso las cosas de esta manera a causa de los defectos del punto de vista marxista que considera los modos de producción como base económica, lo que le ha valido la crítica e incluso el rechazo definitivo al concepto de base económica. Entre la variedad de críticos a la visión marxista, podríamos citar a Weber como uno de los primeros y más significativos. Reconociendo en principio el materialismo histórico, Weber afirmó la autonomía relativa de la estructura ideal. Por ejemplo, mientras que el marxismo considera la Reforma (el protestantismo) de la temprana Edad Moderna como producto del desarrollo de la economía capitalista, Weber subraya, contrariamente, que esta Reforma funcionó como una

${ }^{1}$ Este argumento mío no se contradice con el de Marx. En la etapa de La Ideología Alemana, Marx empleaba la expresión "fuerza productiva y el intercambio" en vez de la "fuerza productiva y las relaciones de producción". Su concepto de intercambio (Verkehr) abarca las relaciones de producción, el tráfico, el comercio, el coito y hasta la guerra. Es decir, abarca los varios tipos de "intercambio" entre las comunidades. Por lo tanto, se puede decir que lo que denomino modos de intercambio se corresponde a lo que Marx indicó con la palabra Verkehr. Mientras tanto, el punto de vista de los modos de producción (la fuerza productiva y las relaciones de producción) pasa por alto el hecho de que la relación entre la naturaleza y el hombre es un intercambio (metabolismo), por lo que pierde la comprensión ecológica que dicha noción marxiana contenía originalmente. 
fuerza promotora del capitalismo industrial (La ética protestante y el espiritu del capitalismo). Es decir, considera que la superestructura como la religión no sólo está determinada pasivamente por la base económica, sino que más bien tiene un poder que afecta activamente a ésta última.

Otro crítico al que menciono aquí es Freud:

La fuerza del marxismo no reside evidentemente en su concepción de la historia ni en la previsión del futuro basada en aquella, sino en su penetrante demostración del influjo necesario que las relaciones económicas entre los hombres ejercen sobre sus posturas intelectuales, éticas y artísticas. Así se descubrieron una serie de nexos y de relaciones de dependencia que hasta entonces se habían ignorado casi por completo. Pero no puede admitirse que los motivos económicos sean los únicos que presiden la conducta de los hombres dentro de la sociedad. Ya el hecho indubitable de que diversas personas, razas, pueblos, se comporten de manera diferente bajo idénticas condiciones económicas excluye el imperio exclusivo de los factores económicos. No se entiende cómo se podrían omitir factores psicológicos toda vez que se trata de las reacciones de seres humanos vivientes, pues no sólo estos han participado en el establecimiento de tales relaciones económicas, sino que, aun bajo su imperio, los seres humanos no podrían hacer otra cosa que poner en juego sus originarias mociones pulsionales: su pulsión de autoconservación, su placer de agredir, su necesidad de amor, su esfuerzo hacia la ganancia de placer y la evitación de displacer. En una indagación anterior hemos reconocido asimismo la vigencia del sustantivo reclamo del superyó, que subroga la tradición y las formaciones de ideal del pasado y resistirá durante un tiempo a las impulsiones provenientes de una situación económica nueva (Freud, 1991: 164-165). 
Freud argumenta que debemos rechazar el "imperio exclusivo de los factores económicos" y tener en cuenta los "factores psicológicos". Cité especialmente este texto porque su crítica está relacionada con las posteriores críticas al materialismo histórico, es decir, con la afirmación de que la superestructura ideal es una entidad relativamente independiente de la base económica.

Este problema comenzó a hacerse consciente entre los marxistas en la década de 1920, cuando sus movimientos llegaron a experimentar serios fracasos. El primero en abordar el problema en cuestión es Gramsci, quien fracasó en el levantamiento revolucionario en Italia y fue encarcelado bajo el régimen fascista. Gramsci consideró que la fortaleza del poder estatal italiano se basaba no simplemente en la coerción violenta, sino que se formaba a través del consentimiento voluntario de los sometidos, lo que él denominó "hegemonía". Esto implica que el Estado no es un mero "aparato violento" de la clase dominante económica, sino un aparato que posee su propio "poder". Es decir, a pesar de determinarse por la base económica, la superestructura tiene una autonomía relativa.

Otra fuente que planteó preguntas serias en torno al poder estatal fueron los marxistas rusos que habían logrado la victoria de los movimientos revolucionarios que impulsaron. Engels escribió después de la muerte de Marx:

Marx y yo habíamos tenido, desde 1845, la opinión de que uno de los posibles éxitos de la revolución proletaria en el futuro deberá ser la disolución gradual de la organización política que se denomina Estado. El objetivo principal de esta organización era, desde siempre, el garantizar mediante la fuerza armada la opresión económica de la mayoría de los trabajadores por parte de una exclusiva minoría de pudientes. Con la desaparición de esta minoría de pudientes, desaparece también la necesidad de esta medida de represión armada, es decir, el poder estatal. Al mismo tiempo, 
sin embargo, nuestra opinión era siempre la siguiente: para lograr tanto este fin como los demás objetivos mucho más importantes de la revolución social del futuro, la clase trabajadora tiene que, en primer lugar, tomar posesión de la fuerza política organizada del Estado, y con esta ayuda, reprimir a la resistencia de la clase capitalista y organizar nuevamente la sociedad (Marx, 1987: 344).

Siguiendo precisamente esta idea, Lenin y Trotsky se atrevieron a llevar a cabo la Revolución de Octubre (el golpe de Estado). En otras palabras, pensaron que el Estado desaparecería gradualmente si el proletariado tomaba posesión del poder estatal y abolía el modo de producción capitalista. Es cierto que este modo de producción había sido abolido por el poder estatal pero, en contra de lo esperado, se produjo una gigantesca ampliación del poder estatal y una intensificación del nacionalismo: el estalinismo. No podemos considerar, sin embargo, que esto se debió a la persona Stalin. Esto demuestra, más bien, los puntos ciegos de la comprensión marxista sobre el Estado. Y tal reflexión también formaba parte de los motivos que incitaron a los marxistas para dar importancia a la superestructura política.

Otro de los ejemplos que podemos citar, en los que se pone en duda la fórmula del materialismo histórico desde el marxismo, corresponde al caso de la Escuela de Frankfurt en Alemania, cuyos miembros experimentaron una derrota ante el nazismo en la década de 1930. Esta derrota fue para ellos una experiencia que los puso a prueba, porque el nazismo era, a diferencia del mero movimiento antirrevolucionario, una contrarrevolución que pretendía, por sí misma, llevar a cabo una revolución. La derrota significaba, para ellos, una derrota ante el "poder" que consistía en la "superestructura política-ideal” (el Estado, la nación, la religión, etc.). Los filósofos lo tomaron en serio y se dirigieron al reexamen del fundamento de la teoría marxista. En otras palabras, examinaron 
la naturaleza de la estructura política-ideal reconociendo su autonomía relativa. Al hacerlo, introdujeron el psicoanálisis freudiano, que hasta entonces habían rechazado por considerarlo una psicología burguesa.

Asimismo, también en el Japón de la década de 1930, los movimientos marxistas se derrumbaron bajo la presión del "fascismo imperial", lo que produjo una conversión colectiva. ${ }^{2}$ Podemos nombrar al politólogo Masao Maruyama y al crítico literario Takaaki Yoshimoto como los pensadores que reflexionaron este suceso después de la guerra y emprendieron el reexamen del marxismo. El primero introdujo la teoría de Weber y la sociología norteamericana, mientras que el último teorizó la autonomía de la superestructura bajo la denominación de "fantasía comunal". A pesar de la diferencia entre las argumentaciones, ambos trataron de descubrir la autonomía relativa de la superestructura, y en este punto, eran paralelos a la Escuela de Frankfurt. Sin embargo, sus teorías tuvieron por efecto la atribución de mayor importancia a la superestructura política-ideal, prestando poca atención a la base económica.

Lo que Louis Althusser llevó a cabo en la Francia de la década de 1960 también coincide con ellos. Althusser introdujo (a través de Lacan) el psicoanálisis freudiano para resolver las dificultades inmanentes del materialismo histórico. Freud denominó "sobredeterminación" a la situación donde la convergencia de múltiples causas produce un solo efecto (2001a: 131). Siguiendo este método, Althusser explicó que los variados modos de producción en la base (la última instancia) "sobredetermina" la superestructura ideal. Sin embargo, este "determinismo" es, en efecto, un argumento que rechaza el determinismo económico y confirma la au-

${ }^{2}$ Karatani se refiere aquí al llamado tenkō: el abandono del marxismo o comunismo por parte de los intelectuales, jurado ante la autoridad o anunciado por medio de alguna publicación [N. del T.]. 
tonomía relativa de la superestructura. Althusser también afirmó acerca del Estado que éste no simplemente consistía en un mero aparato violento de la clase dominante, sino que incluía los aparatos ideológicos que conducían a las personas a obedecerle voluntariamente. Ellos también son entes que existen independientemente del modo de producción que se da en la base económica.

Estas teorías no rechazan el hecho de que la superestructura política-ideológica sea determinada por la base económica. Al contrario, fueron elaboradas para apoyar la noción de la determinación de la base económica. No obstante, cuanto más las elaboraron los teóricos, tanto más tendieron a restarle importancia. Al fin y al cabo, esta tendencia condujo a una indiferencia hacia el mismo marxismo.

Entre las obras de Marx, he concedido importancia únicamente a su libro principal, El capital. He pensado que, en comparación con él, la teoría del materialismo histórico no era más que un somero "hilo conductor". De hecho, el mismo Marx lo comenta:

El resultado general al que llegué y que una vez obtenido sirvió de hilo conductor a mis estudios puede resumirse así: en la producción social de su vida los hombres establecen determinadas relaciones necesarias e independientes de su voluntad, relaciones de producción que corresponden a una fase determinada de desarrollo de sus fuerzas productivas materiales. El conjunto de estas relaciones de producción forma la estructura económica de la sociedad, la base real sobre la que se levanta la superestructura jurídica y política y a la que corresponden determinadas formas de conciencia social. El modo de producción de la vida material condiciona el proceso de la vida social política y espiritual en ge- 
neral. No es la conciencia del hombre lo que determina su ser sino, por el contrario, el ser social es lo que determina su conciencia [...] Al cambiar la base económica se transforma, más o menos rápidamente, toda la inmensa superestructura erigida sobre ella. Cuando se estudian esas transformaciones hay que distinguir siempre entre los cambios materiales ocurridos en las condiciones económicas de producción y que pueden apreciarse con la exactitud propia de las ciencias naturales, y las formas jurídicas, políticas, religiosas, artísticas o filosóficas, en una palabra, las formas ideológicas en que los hombres adquieren conciencia de este conflicto y luchan por resolverlo [...] A grandes rasgos, podemos designar como otras tantas épocas de progreso en la formación económica de la sociedad el modo de producción asiático, el antiguo, el feudal y el moderno burgués. Las relaciones burguesas de producción son la última forma antagónica del proceso social de producción; antagónica, no en el sentido de un antagonismo individual, sino de un antagonismo que proviene de las condiciones sociales de vida de los individuos. Pero las fuerzas productivas que se desarrollan en la sociedad burguesa brindan, al mismo tiempo, las condiciones materiales para la solución de este antagonismo. Con esta formación social se cierra, por lo tanto, la prehistoria de la sociedad humana (2015: 248-249).

Esta clase de perspectiva llegó a conocerse como materialismo histórico. Sin embargo, debemos prestar atención al hecho de que ella no representa el método que Marx adoptó para esclarecer la economía capitalista, es decir, el método de El capital. Lo que se encuentra implicado en el argumento de Marx es que, aun si aquel "resultado general" sirve de "hilo conductor" para considerar la historia general de las formaciones sociales, él mismo adoptará otro punto de vista para la "crítica de la economía política" que emprenderá en adelante. 
¿Por qué Marx se expresa de esta manera? Uno de los motivos es que el materialismo histórico que se basa en los modos de producción es la perspectiva que Engels propuso primero. Después de la muerte de Marx, Engels lo mencionó como el invento epocal de Marx, pero lo cierto es que no fue así. ${ }^{3}$ Engels lo ideó en la época en que Marx todavía estaba bajo la influencia de los jóvenes hegelianos de Alemania. La razón es que Engels estaba en Inglaterra y tuvo la oportunidad de presenciar el desarrollo de la economía capitalista y la lucha de clases (movimientos obreros) que la caracteriza. A partir de esta experiencia, volvió la vista hacia la historia de la sociedad. La fórmula del materialismo histórico es una proyección de la perspectiva que se estableció en la sociedad capitalista sobre las sociedades precedentes. En este sentido, aunque sirva de "hilo conductor" para comprender las sociedades precapitalistas, es inútil para captar la economía capitalista. Por esta razón, Marx introdujo otro punto de vista.

Según la perspectiva del materialismo histórico, las relaciones productivas entre el capitalista y el obrero se dan como fundamento de la sociedad capitalista. En El capital, sin embargo, Marx comenzó no con ellas sino con el intercambio (de dinero y mercancía). ¿Por qué? Por lo general, en el materialismo histórico o el marxismo que se basa en él, la producción se considera como primaria y el intercambio como secundario. Esta perspectiva se

${ }^{3}$ Engels dice: "Estos dos grandes descubrimientos: la concepción materialista de la historia y la revelación del secreto de la producción capitalista, mediante la plusvalía, se los debemos a Marx" (1980: 74). Más tarde, después de la muerte de Marx, Engels comenzó a propagarlo como doctrina del "marxismo". Sin embargo, como Wataru Hiromatsu lo ha apuntado desde hace mucho, esto no fue verdad. Fue Engels el que primero propuso la "concepción materialista de la historia" (materialismo histórico) en la década de 1840. Así mismo, es evidente que el trabajo conjunto de ambas personas -La ideología alemana, especialmente su primera parte "Feuerbach"-, también fue escrito bajo la iniciativa de Engels. 
apoya, más bien, en la de los economistas clásicos que Marx intentó criticar, incluyendo Adam Smith. Ellos pretendieron rechazar el capital comercial, que obtenía ganancias a través del intercambio, y las teorías de los predecesores mercantilistas y bullionistas, cuyo pensamiento se basaba en el capital comercial. En otras palabras, los economistas clásicos afirmaron que las ganancias del capital industrial, a diferencia de las del capital comercial, eran legítimas. En definitiva, esto quiere decir que para ellos el intercambio no era más que secundario.

En contraste, Marx concedió importancia al intercambio, con la intención de reexaminar las cuestiones que habían sido negadas por la economía clásica. En este sentido, podemos decir que él examinó el capital remontándose al mercantilismo y al bullionismo. En su perspectiva, el capitalismo es, en su esencia, capital comercial o capital usurario. El mercantilismo y el bullionismo demuestran que lo que impulsa al capital no es el deseo de los objetos sino el deseo del dinero, es decir, la voluntad de acumular el "poder" que posibilita la obtención de los objetos a través del intercambio. Y la acumulación de este poder se realiza sólo adquiriendo el margen de ganancias (el plusvalor) a través del intercambio. ${ }^{4}$

${ }^{4}$ El capital comercial adquiere ganancias comprando una mercancía en una región (sistema de valor) donde es barata y vendiéndola en otra donde esta última es cara. Como se realiza el intercambio equivalente en ambas regiones, el capital comercial no puede ser considerado una estafa. Mientras tanto, en palabras simples, el capital industrial realiza el plusvalor mediante el proceso en que el obrero vende la mercancía fuerza de trabajo al capital y, al mismo tiempo, como comprador, vuelve a comprar los productos que produjo bajo el capital. En este caso, la razón por la cual surge el margen de ganancias a través del "intercambio equivalente" es que, gracias a la innovación técnica llevada a cabo por parte del capital, el sistema de valor se ha diferenciado. Mientras que el capital comercial se apoya en la diferencia espacial, el capital industrial se apoya en la diferenciación temporal. Por esta razón, bajo el capital industrial, la 
Aquí la cuestión es de dónde surge este "poder" (el valor de cambio). Marx lo descubrió como un tipo de poder espiritual que se adhiere a la mercancía, es decir, como un "fetiche". Éste no permanece en el estado de comprensión relatado en el comienzo de El capital. En este libro, Marx intentó comprender el proceso histórico en el cual el fetiche de la mercancía se desarrolla hasta el fetiche del dinero y el fetiche del capital para reorganizar la formación social en todos sus aspectos. Cuando era joven, Marx criticó la concepción idealista de la historia de Hegel y subrayó el papel materialista de la base económica, pero en El capital, tal como está especificado en el Prefacio, elogia más bien a Hegel, siguiendo fielmente la narración de su Fenomenología del espíritu y de su Ciencia de la lógica, que relata el proceso donde el espíritu se desarrolla a partir de su forma sensible hasta llegar a su autorrealización. Por supuesto, en El capital, el "espíritu" está invertido en la forma del "fetiche". Sin embargo, lo que este libro revela es que la economía capitalista, lejos de ser material, es fetichista, es decir, es el mundo en el que un poder ideal prevalece.

Las características de la sociedad capitalista no se pueden comprender en términos de los modos de producción, pues éstas se manifiestan en un cierto modo de intercambio. En términos concretos, las relaciones entre el capitalista y el obrero se basan en un acuerdo o contrato entre el capitalista que posee el dinero y el obrero que posee la mercancía fuerza de trabajo. Por lo tanto, es heterogénea de las que se dan entre el señor feudal y el siervo en la Europa medieval, así como es diferente de las que se encuentran entre el ciudadano y el esclavo en la Grecia y la Roma antiguas. Es decir, la diferencia entre las relaciones productivas en el sistema capitalista y las que lo preceden consiste en la diferencia entre los

innovación técnica se fomenta constantemente para realizar un aumento de la productividad sin precedente. 
modos de "intercambio". El materialismo histórico considera los relevos de las formaciones sociales como etapas del desarrollo de las relaciones productivas. Sin embargo, los relevos de los modos de intercambio existen, en realidad, en una dimensión más fundamental.

La sociedad capitalista moderna es una sociedad en la que el modo de intercambio mercantil llegó a ser predominante, aunque los otros modos de intercambio siguen permaneciendo activos. La "fuerza productiva y las relaciones de producción" de esta sociedad no son más que el resultado de esta transformación. Por lo tanto, al estudiar la economía capitalista, Marx comenzó por analizar un modo de intercambio, mientras encargaba al "hilo conductor" del materialismo histórico el estudio de las sociedades precedentes a la sociedad capitalista. Sin embargo, la verdad es que la aplicación de los modos de producción, incluso a las etapas precapitalistas, no da lugar a explicaciones satisfactorias. Si el mismo Marx hubiera abordado este estudio, habría adoptado otro método al analizar las formaciones sociales precapitalistas. Esto es evidente, como lo mencionaré más adelante, a partir de sus apuntes sobre La sociedad antigua de L. H. Morgan, por la cual mostró especial interés en sus últimos años de vida.

En general, los marxistas no lograron resultados en cuanto al conocimiento sobre las sociedades precapitalistas, pues les aplicaron la fórmula del materialismo histórico. En efecto, la consideración epocal sobre la formación social tribal (o de clanes) no provino de un marxista, sino de Marcel Mauss, quien estudió esta formación social no en términos de la fuerza productiva ni de las relaciones de producción, sino en términos de un tipo de intercambio, que no es intercambio de mercancías, sino el intercambio recíproco de don-contradón. Yo lo denomino modo de intercambio A, distinguiéndolo del intercambio de mercancías (el modo de intercambio C). Aquel intercambio se lleva a cabo bajo las tres reglas de regalar 
el don, de recibir el don y de devolver el contradón. Estas reglas no son una creación humana, sino que se engendraron bajo la fuerza obligatoria de un "poder mágico" ( hau), al cual el hombre no tiene más remedio que obedecer. La formación social de clanes tiene su fundamento en este principio de intercambio. En este mismo sentido, su estructura de parentesco también se forma a través del intercambio recíproco, donde una comunidad dona a otra a sus hijas o hijos y recibe a cambio un contradón. De esta manera, lo que forja la formación social tribal es un intercambio en su sentido amplio, que es precisamente la base económica de esta sociedad.

Por otra parte, el antropólogo marxista Marshal Sahlins descubrió el "modo de producción doméstico" como el fundamento del intercambio recíproco, mientras que Maurice Godelier apuntó allí una propiedad comunal no transferible (ver Sahlins, 1977; Godelier, 1998). Aun cuando ellos trataron de conservar a toda costa el marco del materialismo histórico se debe reconocer que, en realidad, es el modo de intercambio recíproco el que produjo el modo de intercambio doméstico o la propiedad comunal, y no al revés. Por esta razón, en cuanto a las sociedades primitivas, debemos comenzar nuestra investigación por el modo de intercambio. Y para hacerlo, también podemos consultar las observaciones que Marx hace al respecto.

En sus últimos años de vida, al argumentar sobre la sociedad de clanes elogiando La sociedad antigua de L. H. Morgan, Marx no mencionó el "modo de producción”. Marx no prestó atención a la igualdad económica en la sociedad de clanes, sino más bien a la libertad e independencia de los individuos miembros: "Todos los miembros de una gens iroquesa 'eran' libres, estando obligados a defender la libertad de cada uno de ellos; iguales en privilegios y derechos personales. No correspondía superioridad alguna a los sachem y jefes; una fraternidad mutuamente vinculada por lazos de parentesco. Libertad, Igualdad y Fraternidad, aunque nunca 
formuladas, eran principios cardinales de la gens y ésta la unidad de un sistema social y gubernamental en el que se basaba la organización de la sociedad india" (1988: 124).

Entonces, ¿¿de dónde surge el principio de "Libertad, Igualdad y Fraternidad" en la sociedad de clanes? No podemos explicarlo en términos del modo de producción o de la propiedad comunal. Aunque Marx no hizo ningún comentario sobre esta cuestión, este principio emerge, bajo mi perspectiva, del principio de intercambio recíproco, que es la base económica que determina esta sociedad. Además, Marx sostuvo que el comunismo futuro sería una "restauración" del principio de la sociedad de clanes "en una mayor dimensión”. Esto significa que Marx no consideró el comunismo futuro simplemente como una etapa desarrollada de un modo de producción. Aun si no lo afirmó claramente, podemos decir que Marx sugirió que debiéramos considerar el comunismo futuro desde el punto de vista de los modos de intercambio. Lo mencionaré más adelante.

Ahora, ¿cómo podemos ver la sociedad Estatal, que nació después de la sociedad de clanes? Pareciera ser que esta sociedad se basa en una explotación violenta, pero en realidad, se basa en un "intercambio" -aunque no se considera en general como tal- donde uno se somete al otro para recibir su protección. ${ }^{5}$ El Estado se origina como una conquista y dominación a través de la violencia, pero puede ser una dominación continua cuando el dominado se

${ }^{5}$ En Leviatán, Hobbes describe que, a partir de la "condición natural" en que todos luchan contra todos, un estado de paz se establece a través de un contrato social, que es, según él, un "pacto estipulado por temor". Es un intercambio, porque el que se somete "recibe el beneficio de la vida" a cambio de ello (2005: 114). Por otra parte, el gobernante tiene la obligación de llevarlo a cabo. En este sentido, podemos decir que Hobbes comprende el Estado en términos del modo de intercambio B. En contraste, los pensadores posteriores, incluyendo a Locke, consideran el contrato social en términos del modo C. 
somete voluntariamente. Esto es posible sólo cuando la sumisión significa recibir una protección, es decir, la relación gobernantegobernado se convierte en un tipo de intercambio. Este intercambio produce un "poder", que es diferente de la violencia. Este poder vincula no solamente al gobernado sino también al gobernante, pues si el gobernante no puede proteger al gobernado, pierde el derecho de ocupar la posición de gobernante. En este sentido, esta relación es bilateral (recíproca) y, en cierto sentido, tiene relación con el modo de intercambio A.

Yo denomino a este modo de intercambio modo B. Así como en el caso del modo de intercambio A, en el modo B también actúa un "poder" no físico. Este poder nace a través del mismo intercambio, y no es algo que surja de alguna parte de la superestructura ideal. Cuando vemos los modos de intercambio como base económica, podemos comprender que el Estado no deriva de la superestructura visto como algo diferente de la dimensión económica, sino que se basa directamente en una forma de intercambio, es decir, una base económica en su sentido amplio. La "hegemonía” de Gramsci, el "aparato ideológico" de Althusser y la relación "poder-saber" de Foucault no son parte de la superestructura, sino que se derivan de la base económica. Además, lo que de hecho Freud consideró como "factores psicológicos", distinguiéndolo de los factores económicos, también poseen un origen en un modo de intercambio, es decir, tienen lugar en la base económica en su sentido amplio.

Ahora bien, ¡cómo es el caso del modo de intercambio C? Como he mencionado, pareciera ser que este modo se trata del mero intercambio material, pero en realidad no es así. Allí también existe un poder ideal, que deriva del mismo "intercambio". Marx dice: "el intercambio de mercancías comienza donde terminan las entidades comunitarias, en sus puntos de contacto con otras entidades comunitarias o con miembros de éstas" (2008: 107). En 
otras palabras, el intercambio se lleva a cabo con otros desconocidos que no son de fiar. Por lo tanto, requiere un "poder" que obliga a los otros, un poder que es heterogéneo al de la comunidad o del Estado. También es un poder ideal-religioso. En términos vulgares, se llama "crédito". Marx lo llamó fetiche: "El enigma que encierra el fetiche del dinero no es más, pues, que el enigma, ahora visible y deslumbrante, que encierra el fetiche de la mercancía” (2008: 113). De esta manera, Marx intentó demostrar el proceso mediante el cual el fetiche de la mercancía se convierte en el fetiche del dinero y luego en el fetiche del capital para dominar a la sociedad entera. Lo que El capital aclaró es que, reitero, la economía capitalista, lejos de ser material, corresponde a un mundo que está bajo la dominación de un poder fetichista, es decir, un poder ideal (véanse las figuras 1, 2 y 3).

Figura i. Modos de Intercambio BÁsicos

\begin{tabular}{|c|c|}
\hline $\begin{array}{c}\text { B Sumisión y Protección } \\
\text { (Saqueo y Redistribución) }\end{array}$ & $\begin{array}{c}\text { A Reciprocidad } \\
\text { (Don y Contradón) }\end{array}$ \\
\hline $\begin{array}{c}\text { C Intercambio de Mercancías } \\
\text { (Dinero y Mercancía) }\end{array}$ & D Reciprocidad de la Libertad \\
\hline
\end{tabular}

Figura 2. Formaciones Sociales Básicas

\begin{tabular}{|c|c|}
\hline B Estado & A Comunidad \\
\hline C Ciudad (Mercado) & D X \\
\hline
\end{tabular}


Figura 3. Formas de Poder Derivado del Intercambio

\begin{tabular}{|c|c|}
\hline B Poder Político & $\begin{array}{c}\text { A Poder Mágico } \\
\text { (Fetiche) }\end{array}$ \\
\hline $\begin{array}{c}\text { C Poder Dinerario } \\
\text { (Crédito) }\end{array}$ & $\mathrm{D} \mathrm{X}$ \\
\hline
\end{tabular}

Lo que queda demostrado en lo mencionado es que los modos de intercambio $\mathrm{A}, \mathrm{B}$ y $\mathrm{C}$ producen, respectivamente, un "poder" ideal que obliga al hombre. Todos estos poderes derivan precisamente del "intercambio". Sin embargo, desde la perspectiva que considera los modos de producción como la base económica, aquellos factores religioso-políticos se ven como derivaciones de la superestructura que está por encima de la base económica. Por lo tanto, el estudio de estos factores se entrega a la antropología, a las ciencias políticas o a las ciencias religiosas. Lo único que los marxistas pueden hacer es otorgarles a estas ciencias el concepto de modo de producción como la base económica, que no es más que una extrapolación. Como resultado de esto, la base económica prácticamente se ignora. Por otra parte, la antropología, las ciencias políticas o las ciencias religiosas que han sido aparentemente liberadas de la base económica, en realidad, no lo están. Sólo se encuentran en una situación intelectual deplorable - no cuestionan de dónde viene el "poder" ideal descubierto en cada campo de estudio, ni tienen necesidad de cuestionarlo, e incluso, ni saben cómo cuestionarlo-, tan deplorable que no tienen conciencia de estar en la misma.

Frente a esto, he planteado estudiar los modos A y B, como Marx lo hizo respecto del modo $\mathrm{C}$ en El capital, persiguiendo el desarrollo de cada uno desde su fase embrionaria hasta la actual. Sin embargo, los modos A, B y C no existen por separado, pues una formación social se compone de la combinación de éstos. Por 
lo tanto, no podemos tratar un solo modo, sino que tenemos que tener en consideración los demás modos de forma simultánea. En cuanto a esto, cuando Marx trató los problemas que derivan del modo C en El capital, los analizó poniendo entre paréntesis los factores de los modos A y B, es decir, la comunidad y el Estado. La real economía capitalista no puede existir si excluye la existencia del Estado o de la comunidad. No obstante, Marx los puso entre paréntesis para captar las características del modo C. ${ }^{6}$

Por consiguiente, debemos considerar la historia de las formaciones sociales como un complejo de los diversos modos de intercambio: cada modo de intercambio se modifica conforme a las transformaciones de las formaciones sociales. La primera formación social emerge bajo la forma de la sociedad de clanes, donde el modo A es predominante. En esta etapa ya actúan también los modos B y C, aunque en menor grado. El modo B llega a ser predominante en la etapa de la sociedad Estatal, pero el modo A no desaparece. Éste último persiste dentro de la comunidad agraria que se subordina al Estado. Aunque esta comunidad es dependiente del poder del orden mayor, es un grupo autónomo e igualitario en su interior. Además, bajo el dominio del modo B, la ciudad se desarrolla a través del comercio entre las comunidades, que expande el modo de intercambio C. Por otro lado, junto con ello, el modo B se extiende aún más para formar un "imperio mundial". Esta situación sufre una transformación en la etapa en que, junto con el establecimiento del mercado mundial, el modo $\mathrm{C}$ se expan-

${ }^{6}$ La razón por la cual Marx pudo poner al Estado entre paréntesis, cuando emprende su estudio sobre el capitalismo, es que su objeto de investigación era la Inglaterra de la época del liberalismo. Si hubiera tratado la economía capitalista de otro país de la misma época, no habría podido hacer lo mismo. De igual forma, en la época del imperialismo, cuyas características se pusieron de manifiesto después de la muerte de Marx, la economía capitalista británica no pudo ser considerada sin tener en cuenta del papel del Estado. 
de drásticamente: se trata del nacimiento de la formación social moderna.

Para comprender estas coyunturas, necesitamos ver las transformaciones de las formaciones sociales no solamente según el eje temporal, sino también según el eje espacial. Lo que he relatado hasta este momento es un modelo simple de la formación social. Sin embargo, ninguna sociedad existe sola: está en comunicación con otras sociedades. En otras palabras, está en relaciones de "intercambio" con otras sociedades. Llamo esta clase de combinación de las formaciones sociales "sistema-mundo" (sistema mundial), siguiendo a Fernand Braudel. Este sistema tiene varias formas conforme a cuál modo de intercambio es predominante (véase la Figura 4).

Figura 4. Etapas del Sistema Mundial

\begin{tabular}{|c|c|}
\hline B Imperio-Mundo & A Minisistema-Mundo \\
\hline $\begin{array}{c}\text { C Economía-Mundo } \\
\text { (Moderno Sistema Mundial) }\end{array}$ & D República Mundial \\
\hline
\end{tabular}

Por ejemplo, incluso la sociedad de clanes forma un "minisistema-mundo". Éste no necesariamente es pequeño (mini), sino que resulta ser un ejemplar gigantesco tal como la Confederación Iroquesa. Su característica principal consiste en el hecho de que los enlaces entre los clanes se basan de por sí en el modo de intercambio A. El siguiente sistema mundial es el "imperio-mundo", que se basa en el modo de intercambio B. Lo que emerge después es el sistema mundial que Braudel denomina "economía-mundo", donde el modo de intercambio $\mathrm{C}$ es predominante. Sin embargo, aquí también los modos $\mathrm{B}$ y A perviven modificando sus formas. Es decir, el modo B persiste como Estado soberano, mientras que 
el modo A como nación. Por consiguiente, la formación social moderna toma la forma de una combinación de los tres modos de intercambio, es decir, el Estado-Nación-Capital. Podemos llamarlo "moderno sistema mundial", empleando la denominación de Wallerstein (véase la Figura 5).

Figura 5. Moderno Sistema Mundial

(Estado-Nación-Capital)

\begin{tabular}{|c|c|}
\hline B Estado & A Nación \\
\hline C Capital & D X \\
\hline
\end{tabular}

Como lo hemos visto, la historia de las formaciones sociales se puede explicar en términos de las combinaciones de los modos de intercambio como la base económica. Mi libro La estructura de la historia mundial se basa en este esquema teórico.

He argumentado hasta aquí que al considerar el sistema capitalista y las formaciones sociales precedentes a él, necesitamos el punto de vista que considera a los modos de intercambio como la base económica. La verdad es que lo requerimos, más bien, para considerar la sociedad postcapitalista, es decir, el comunismo. Desde el punto de vista de los modos de producción, no podemos aclarar la necesidad del comunismo. Marx dijo: "Para nosotros, el comunismo no es un estado que debe implantarse, un ideal al que haya de sujetarse la realidad. Nosotros llamamos comunismo al movimiento real que anula y supera al estado de cosas actual. Las condiciones de este movimiento se desprenden de la premisa actualmente exis- 
tente" (Marx/Engels, 1970: 37). Al expresarse de esta manera, es cierto que Marx consideraba el comunismo como algo diferente del deseo o del ideal que el hombre suele tener. No obstante, desde el punto de vista de los modos de producción, no podemos descubrir lo que hace necesario al comunismo, es decir, el "poder" que constriñe a los sujetos como causa de que se conduzcan hacia él.

La perspectiva del materialismo histórico considera la "contradicción entre el desarrollo de la fuerza productiva y las relaciones de producción" como el motor principal que impulsa a la historia. También considera que esta "contradicción" se manifiesta bajo la forma de la lucha de clases y que, en definitiva, el comunismo se realizará a través de la "lucha de clases que suprime las clases mismas”. Sin embargo, ¿qué tipo de lucha de clases existía antes de la sociedad capitalista? Como ya he señalado, mientras adoptemos el punto de vista de los modos de producción, no podemos encontrar allí ninguna lucha de clases.

Según dicho punto de vista, en la sociedad feudal, por ejemplo, la lucha de clases debe llevarse a cabo entre los seńores y los siervos, pero como hecho histórico, ella no tuvo lugar casi nunca. Aun si tuvo lugar alguna lucha, eso se debía principalmente al desgobierno de un señor, es decir, cuando el intercambio bilateral (del modo B) no se cumplió entre las dos partes. En suma, aun si existió la lucha, se desarrolló sólo dentro de los límites del modo de intercambio B. En la Edad Media, fue entre los señores y los pueblos urbanos donde estallaron las luchas de clases que pretendían superar al modo de intercambio B. Es decir, fue el modo de intercambio C, que emergió en las ciudades, el que se opuso al modo B. En resumidas cuentas, la "lucha de clases" en la Edad Media no se basa en los términos de los modos de producción, sino que era una lucha entre el modo de intercambio B y el modo de intercambio $\mathrm{C}$, quien se había expandido desde las ciudades. Como sabemos, el ganador definitivo fue el último. 
Siendo este el caso, sin embargo, se trata de una "lucha entre clases" y no una "lucha que suprime las clases mismas". En realidad, aquellas luchas históricas albergaban factores que abolían las clases mismas. Estos factores fueron los que elevaron estas luchas a la "lucha de clase" como hito de una época. En cuanto hechos históricos, ellos no se realizaron plenamente y sólo ayudaron al relevo de la clase gobernante, como podemos ver en el caso de la Revolución Francesa, donde bajo la exaltación del lema "Libertad, Igualdad y Fraternidad", se terminó colaborando con la sociedad capitalista.

Entonces, ¿de dónde surge el movimiento que "suprime las clases mismas"? Por lo general, se considera que proviene de la dimensión religioso-ideológica, es decir, no de la base económica sino de la superestructura ideal. En mi perspectiva, sin embargo, éste también se origina a partir de la base económica, es decir, de un modo de intercambio, que sería diferente de los modos A, B y $\mathrm{C}$, y que pretende abolirlos. Este modo posee, a diferencia de la mera idea, un "poder" compulsivo. Lo mencionaré más adelante.

Lo que queda claro aquí es que lo que ha sido identificado como lucha de clases en la Edad premoderna no derivó, en realidad, de los modos de producción, sino de los modos de intercambio. Lo mismo se puede decir de la lucha de clases en la sociedad capitalista. Como he relatado más arriba, Engels prestó atención a la lucha de clases en la Inglaterra de la década de 1840 para idear el "materialismo histórico". Pero en 1848, cuando se desencadenó el movimiento revolucionario en toda Europa, la lucha de clases en Inglaterra acabó antes que en cualquier otro lugar. Esto no se debió a que el cartismo fue derrotado, sino que en cierta medida logró la victoria. Después de este suceso, en Inglaterra se legalizó el sindicato, y poco después apareció un grupo de personas que se hacían llamar "aristocracia obrera”, estableciéndose luego el fabianismo (la socialdemocracia). En resumidas cuentas, la lucha de 
clases en Inglaterra desapareció junto con cierta victoria de la clase obrera. ¿Por qué?

La razón por la cual la lucha de clases desapareció en ese momento no se debe a que las relaciones de producción capitalista desaparecieron. Como resultado de la lucha, la negociación del salario a través del sindicato o de otros medios fue legalizada. Desde el punto de vista de los modos de intercambio, las relaciones entre el capitalista y el obrero, que anteriormente eran similares a los modos A o B, devinieron en el modo C. Si desde esta perspectiva volvemos la vista atrás, podemos concluir que la intensa lucha de clase de los cartistas se produjo, no a partir de las "relaciones de producción" ni de la "contradicción entre la fuerza productiva y las relaciones de producción”, sino más bien de la emergencia de un nuevo modo de intercambio, que pretendió sustituir al modo de intercambio que era predominante hasta entonces. Cuando este relevo se logró, el movimiento obrero llegó a formar parte del mercado laboral, es decir, de la economía de mercado capitalista. Con este proceso, a pesar de que la lucha de clases sigue existiendo en apariencia, la "conciencia de clase que suprime las clases" desaparece.

En los países capitalistas desarrollados, la lucha de clases o el movimiento revolucionario socialista están destinados a cesar después de llegar un cierto auge. A fines del siglo XIX, después de la muerte de Engels, su discípulo Bernstein proclamó el fin de la teoría revolucionaria de Marx-Engels frente a esta situación. Por otra parte, Lenin consideró que la clase obrera tenía una conciencia burguesa espontánea, y que carecía de la conciencia de clase que suprime las clases, por lo que ésta debía ser introducida "desde fuera”. La Historia y conciencia de clase (1923) de Lukács fue una obra que ofreció el fundamento filosófico a esta opinión. Para ellos, el "afuera" se refiere a las ideas proporcionadas por los intelectuales dirigentes (el Partido). Esta teoría es gemela a la del Rey filósofo de 
Platón, y no resulta ser más que el fundamento, al fin y al cabo, al régimen dictatorial del Partido.

Por otro lado, Ernst Bloch, quien había señalado desde hace tiempo el límite del materialismo histórico, intentó una conjunción de la revolución socialista y la religión en Thomas Münzer como teólogo de la revolución (1921). Aunque Lukács lo criticó como un desvío del marxismo, quisiera llamar la atención al hecho de que Engels se había enfrentado tempranamente con el mismo problema en 1848, y adoptó la misma postura que la de Bloch. En el momento en que la "lucha de clases" cesó en Inglaterra, Engels comenzó nuevamente a preguntar cómo se harían posibles la lucha de clases y la revolución socialista. Esta cuestión no era solucionable desde el punto de vista de la "fuerza productiva y las relaciones de producción”. La misma persona que había propuesto este punto de vista se dio cuenta de ello.

En términos concretos, Engels se dirigió al estudio de los movimientos campesinos de la Alemania del siglo XVI (La guerra campesina en Alemania, 1850), e intentó descubrir allí el "comunismo" en el pensamiento de Thomas Münzer, el dirigente del movimiento milenarista. La teoría propia de Engels era que el "poder" que incita al hombre al socialismo o al movimiento que suprime las clases provenía de la base económica (la contradicción entre la fuerza productiva y las relaciones de producción). Pero él reconoció allí que ese poder surgía de la dimensión ideológico-religiosa. Y hasta sus últimos años de vida, iba a seguir estudiando la historia del cristianismo primitivo. Tengo que concluir, sin embargo, que Engels no profundizó este problema más allá de ese nivel.?

\footnotetext{
${ }^{7}$ La validez de la observación de Engels en La guerra campesina en Alemania no se limita a Occidente ni al mundo cristiano. Por ejemplo, en Japón, durante un largo período del siglo Xvi, se libró una guerra campesina a gran escala. Podemos decir que este suceso coincidió con la transformación de la sociedad que estaba en marcha en aquel entonces bajo el mercado mundial. Sin embargo, debemos
} 
Podemos decir que Bloch sucedió a Engels en este tema. En este sentido, sostuvo lo siguiente: "así llegamos a la posibilidad de la frase: Sólo un ateo puede ser un buen cristiano, pero ciertamente también: sólo un cristiano puede ser un buen ateo" (1983: 16). Por otro lado, el teólogo cristiano Karl Barth mencionó lo siguiente antes que Bloch: "Un célebre teólogo y autor ha argumentado recientemente que estos dos no se deben yuxtaponer como se muestran en nuestro tema 'Jesucristo $y$ el movimiento social', que da la impresión que ellos fuesen entes distintos, que deben ser enlazados, en cierto modo, artificialmente uno al lado del otro. En realidad, ambos deben ser vistos como uno y el mismo: Jesús es el movimiento social, y el movimiento social es Jesús viviente" (1993: 380 y ss). ${ }^{8}$

Se puede decir que estos pensadores se hallaron con el mismo problema que Engels había enfrentado, de tal forma que intentaron superar el abismo entre la religión y el movimiento social, es decir, la ruptura entre la superestructura ideal y la base económica, conectando ambas de manera paradójica. Sin embargo, esta cuestión se resuelve si adoptamos como la base económica los modos de intercambio en vez de los modos de producción. He explicado hasta aquí los tres modos de intercambio, a los que agrego ahora el otro, el modo de intercambio D.

En sentido estricto, el modo D no es un modo de intercambio. Existe como impulso de rechazar y suprimir el "intercambio" (sea del modo A, B o C). Se manifiesta como un poder ideal-religioso. $\mathrm{Al}$ mismo tiempo, tiene un vínculo estrecho con la base económi-

prestar atención al hecho de que emergieron en este momento los factores del modo D a través de una secta budista (Jōdo Shinshū). Esta guerra campesina sufrió una derrota y, como resultado, se estableció el régimen feudal de Tokugawa, adoptándose la política de aislamiento. Este hecho nos recuerda el comentario de Engels de que la derrota de la guerra campesina retrasó la modernidad alemana por doscientos años.

${ }^{8}$ Esta traducción se basa en la edición inglesa (Barth, 1976: 45) [N. del T.]. 
ca, es decir, con el intercambio. Precisamente por esta razón, puede resistirse a los diferentes poderes que derivan de los modos A, B y C. No es un ser imaginario creado por el deseo o la voluntad humana, sino que, contrariamente, tiene un "poder" que obliga al hombre.

Es cierto que el modo $\mathrm{D}$ tiene un carácter religioso por naturaleza. Si éste es el caso, en realidad, los modos $\mathrm{A}, \mathrm{B}$ y $\mathrm{C}$ también son religiosos. Por ejemplo, Weber califica la acción religiosa como "coerción divina", que no es otra cosa que el "intercambio A", donde se hace una donación a un dios para obligarle un contradón. Podemos decir que el Estado también es una religión que se basa en el "intercambio B". Por otra parte, el intercambio C produce otra religión: el fetichismo. Éste, a primera vista, no parece ser una religión. De hecho, actualmente en los países capitalistas desarrollados la secularización, que rechaza a la religión, se encuentra en un estado avanzado. Sin embargo, esta secularización no significa una crítica de la religión, sino que representa la marca del neoliberalismo, es decir, una situación en la que el modo $\mathrm{C}$ ha llegado a ser el fetiche predominante.

El modo D nació, originalmente, como una crítica a todas estas "religiones". En términos concretos, emergió en la etapa del imperio mundial donde los modos $\mathrm{A}, \mathrm{B}$ y $\mathrm{C}$ han llegado a cierta madurez, en varias regiones bajo la forma de las religiones universales. ${ }^{?}$ En otras palabras, las religiones universales aparecieron precisa-

${ }^{9}$ Lo que denomino aquí religión universal es diferente de la religión mundial, que tiene numerosos creyentes en todo el globo. La cuestión de si una religión o una secta constituye una religión universal no depende de su escala. Una religión puede ser universal sólo cuando alberga los factores del modo D. Además, el modo $\mathrm{D}$ se manifiesta no solamente en la religión, sino también bajo la forma de la filosofía, la literatura o el arte. Véase Kojin Karatani, La isonomía y el origen de la filosofía (edición japonesa 2012) en su edición inglesa Isonomia and the Origins of Philosophy (2017). 
mente como una "crítica de la religión". Aunque se transformaron luego en una religión comunitaria (del modo A) o una religión imperial (del modo $\mathrm{B}$ ), los factores del modo $\mathrm{D}$ que residían dentro de estas religiones han resucitado constantemente, tomando forma en los movimientos heréticos, como por ejemplo el movimiento de Thomas Münzer. Por consiguiente, el modo D ha participado históricamente en las transformaciones de las formaciones sociales. En este sentido, podemos decir que, a pesar de no ser un elemento de la formación social, que es un complejo de los modos de intercambio, el modo D ha persistido al interior de ella.

En la formación social moderna, el modo $\mathrm{C}$ se hace predominante. Sin embargo, los modos A y B no desaparecen, sino que perviven transformándose bajo el dominio del modo C. Históricamente, el modo B ha persistido en el Estado moderno que adoptó el sistema jurídico burgués, tomando la forma del "poder estatal". Mientras tanto, el A se ha restablecido, después de la disolución de la organización tribal y la comunidad por parte del C, como una "comunidad imaginada" (Benedict Anderson). En consecuencia, la formación social moderna ha tomado la forma "Estado-NaciónCapital".

En la actualidad, el modo A actúa como promotor del impulso que pretende restaurar la comunidad que existía anteriormente, es decir, como nacionalismo. Sin embargo, éste no puede superar a los modos B y C. Contrariamente, acaba por servir al EstadoCapital demostrando su aspecto chauvinista y xenófobo. Esto es lo que antes llevó al fascismo, y hará lo mismo en el futuro. En contraste, el modo $\mathrm{D}$ no es una restauración de la comunidad del pasado. Su similitud al modo A es sólo en apariencia.

El modo $\mathrm{D}$ es el impulso de rechazar a los modos $\mathrm{A}, \mathrm{B}$ y $\mathrm{C}$ mientras éstos persistan. Ahora bien, ¿de dónde viene este modo? Pareciera venir del mundo celestial, pero lo cierto es que surge de la 
dimensión económica. En otras palabras, parece venir del futuro, pero tiene origen en el pasado.

¿De dónde viene el "poder" del modo D? Esta pregunta es inseparable de la cuestión acerca de dónde deriva el "poder" del modo A, es decir, de cómo se inició el intercambio recíproco. No podemos contestar a esta pregunta con una prueba positiva. Quisiera citar lo que Marx dijo en el prefacio de El capital: "Cuando analizamos las formas económicas, [...] no podemos servirnos del microscopio ni de reactivos químicos. La facultad de abstraer debe hacer las veces del uno y los otros" (2008: 6). Es decir, Marx buscó el origen del modo de intercambio C (mercantil) a través de su "facultad de abstraer". Siguiéndolo a él, podemos aplicar el mismo método en cuanto a los demás modos de intercambio.

No cabe la menor duda de que, en las sociedades primitivas, el intercambio recíproco era el principio constituyente de la formación social. Sin embargo, este intercambio no existía desde el comienzo. En la etapa en que la humanidad era un pueblo nómada de cazadores-recolectores, no existía el modo A, por no hablar nada de los modos B y C. Podemos considerar que los productos se distribuían allí equitativamente, pues los pueblos eran errantes y no podían acumularlos. La escala de una banda nómada no excedía el número de personas requerido para la caza, y tampoco quedó por debajo de él. No había restricción alguna que sujetara a los miembros del grupo. Cuando un grupo se encontró con otro, podía practicar algún intercambio simple, no desembocando en la guerra. Denomino esta situación proto-nomadismo U.

Este panorama cambió cuando los pueblos comenzaron a adoptar el sedentarismo en varias regiones, a causa del cambio climático global. Después de eso, entre los miembros del grupo, llegaron a surgir conflictos interpersonales y desigualdades de riqueza. Además, debido al estilo de vida sedentario, tuvieron la necesidad de realizar el intercambio con otros grupos, que a la vez les provocó 
otras dificultades. Fue en este momento cuando emergió el modo de intercambio A, es decir, la reciprocidad del don. Por supuesto, no se trata de una invención de los pueblos, sino de algo que advino trascendiendo la voluntad humana.

A este respecto, me referiré a la teoría de Freud, pero con un enfoque diferente, distanciándome de lo que él argumentó en Tótem y tabú. En esta obra, Freud intentó explicar los principios que posibilitaban la "alianza fraterna" de la sociedad primitiva, a partir del "asesinato del protopadre" por parte de los hijos-hermanos. Sin embargo, el "protopadre" es una hipótesis que Darwin ideó basándose en una observación de la sociedad de gorilas, y al mismo tiempo, no es más que una proyección del patriarca que emergió en la etapa de la sociedad Estatal en un tiempo inmemorial. Actualmente, la hipótesis freudiana es completamente rechazada. A pesar de ello, creo que podemos explicar el origen del intercambio recíproco a partir de otra teoría de Freud que él mismo no intentó aplicar: la teoría más tardía de Freud en la que él introdujo el concepto de "pulsión de muerte".

La pulsión de muerte es un instinto por el cual el organismo (la vida) tiende a regresar a la sustancia inorgánica: "Partiendo de ciertas especulaciones sobre el origen de la vida y sobre determinados paralelismos biológicos, deduje que, además del instinto que tiende a conservar la sustancia viva y a condensarla en unidades cada vez mayores, debía existir otro, antagónico de aquél, que tendiese a disolver estas unidades y a retornarlas al estado más primitivo, inorgánico" (Freud, 2001b: 63). Esta observación es más bien válida, creo yo, respecto de la formación social que del individuo. Cuando la humanidad era nómada, estaba en un "estado inorgánico". Después de la adopción del sedentarismo, apareció el "estado orgánico”, en el que surgen las desigualdades y los conflictos.

Lo que pretende recuperar el "estado inorgánico" en ese momento es la pulsión de muerte, que se dirige primero hacia fuera en 
la forma de la agresividad. Pero en términos freudianos, al dirigirse hacia dentro, ésta se convierte en el superyó que pretende controlar la agresividad del yo. Podemos suponer que el intercambio recíproco del don apareció de tal modo. El hombre tiene la obligación de regalar el don, de recibir el don, y de devolver el contradón. En este caso, parece que algo espiritual que se adhiere al objeto donado obliga al hombre a hacerlo. Sin embargo, podríamos decir que la razón por la cual el "poder" del modo A es compulsivo-repetitivo reside en el retorno del proto-nomadismo U que se perdió a causa de la sedentarización. Éste actuó, de hecho, como el poder ideal que impide la génesis de las clases y el Estado.

Después de la sociedad de clanes, la sociedad humana llegó a ser gobernada por los "poderes" ideales que los modos $\mathrm{B}$ y $\mathrm{C}$ producen. Por su parte, el modo A acabó constituyéndose, bajo el dominio del B, como el principio de la comunidad. Como he mencionado, sin embargo, cuando los modos A, B y C llegaron a cierta etapa del desarrollo, es decir, en la etapa del imperio mundial, el modo $\mathrm{D}$ apareció bajo la forma de la religión universal. La religión universal es el modo D, y el modo D es la religión universal. En otras palabras, la religión universal no puede existir independientemente de la base económica.

El modo D no es el retorno del modo A, sino el retorno del U. ${ }^{10}$ Por lo tanto, no se orienta hacia el pasado, sino hacia el futuro. Sin embargo, es compulsivo-repetitivo, por lo que está por encima del deseo o la fantasía humana. Lo que el modo $\mathrm{D}$ posibilita son varias formas de oposición contra los "poderes" que los modos A, B y C producen. Entre aquellas formas, podemos incluir la literatura y el arte. Es precisamente el modo D el que manifiesta, a través de

${ }^{10}$ En Moisés y la religión monoteista, Freud intentó especular sobre el origen de la religión universal, considerándolo como una cuestión extensiva de lo que él propuso en Tótem y tabú, es decir, como una cuestión edípica. En realidad, Freud debió tratar ambas cuestiones desde el punto de vista de la "pulsión de muerte". 
la literatura y el arte, no solamente la determinación de la fuerza productiva y las relaciones de producción, sino una utopía que las trasciende. Ernst Bloch desarrolló sus misteriosas argumentaciones para ofrecerle un fundamento "ontológico" a este asunto, pero si lo consideramos materialistamente, es decir, en términos de los modos de intercambio, no hay ningún misterio allí.

Mientras persistan los poderes de los modos A, B y C, el modo $\mathrm{D}$ retornará compulsivamente para suprimirlos. Por lo tanto, el "comunismo" es, en la medida en que consiste en el modo D, históricamente necesario. Lo que se ha mencionado hasta aquí son los puntos esenciales de mi argumentación en La estructura de la historia mundial.

(Traducción de Yutaka Makioka y Andrea Ugalde)

\section{Bibliografía}

Barth, Karl, 1976, "Jesus Christ and the Movement for Social Justice", en George Hunsinger (ed.), Karl Barth and Radical Politics, Westminster Press, Philadelphia,.

, 1993, "Jesus Christus und die soziale Bewegung [Jesucristo y el movimiento social]" (1911), en Karl Barth, Vorträge und kleinere Arbeiten: 1909-1914, Gesamtausgabe, Band 22. Abt. III, Theologischer Verlag, Zurich.

Bloch, Ernst, 1983, El ateísmo en el cristianismo, Taurus, Madrid.

Engels, Friedrich, 1980, "Del socialismo utópico al socialismo científico" (1880), en Marx y Engels, Obras escogidas, t. III, Progreso, Moscú. 
Freud, Sigmund, 1991, "Nuevas conferencias de introducción al psicoanálisis", en Sigmund Freud, Obras completas, vol. 22, Amorrortu, Buenos Aires, pp. 164-165.

, 2001a, Moisés y la religión monoteísta, Alianza, Madrid.

, 2011b, El malestar en la cultura, Alianza, Madrid.

Godelier, Maurice, 1998, El enigma del don, Paidós, Barcelona.

Hobbes, Thomas, 2005, Leviatán, Fondo de Cultura Económica, Buenos Aires.

Karatani, Kojin, 2017, Isonomia and the Origins of Philosophy, Duke University Press, Carolina del Norte.

Marx, Karl, 1987, “Zum Tode von Karl Marx [A la muerte de Karl Marx] (Mayo 1883)", en Karl Marx y Friedrich Engels, Werke, Band 19, Dietz Verlag, Berlín, p. 344.

, 1988, "Extractos de Marx, tomados de Lewis Henry Morgan, Ancient society", en Los apuntes etnológicos de Karl Marx, transcritos, anotados y introducidos por Lawrence Krader, Siglo XXI, Madrid.

,2008, El capital, t. I, vol. I, Siglo XXI, México.

, 2015, "Contribución a la crítica de la economía política (Prólogo)", en Karl Marx, Antología, Siglo XXI, Buenos Aires, pp. 248-249. Barcelona.

Sahlins, Marshall, 1977, Economía de la edad de piedra, Akal, Madrid. 